\title{
INTEGRATED PARAMETER TEST SYSTEM FOR DUAL FUEL ENGINES OF SPECIAL HEAVY VEHICLES
}

\author{
Xuejun Zhu \\ Automobile Institute, Henan College of Transportation, Zhengzhou, 450005, China \\ Email: hnccycz@163.com
}

\begin{abstract}
The comprehensive parameters of a dual-fuel engine for special heavy vehicles directly reflect vehicle performance. This paper takes the Yuchai YC6K420 series of inline six-cylinder CNG/dual fuel engine special heavy-duty vehicles as an example to build the comprehensive parameter test system for the engine. The PXI 6251 capture card is used to acquire engine analog signals. The fuel consumption and gas consumption meters of three German Endress + Hauser (E + $\mathrm{H})$ companies are combined to measure, display and store fuel consumption and gas consumption data. The system data acquisition program mainly includes channel creation, configuration and signal acquisition, which can realize system data reading, filtering conditioning, display and save. The electronic control unit in the system uses the periodic interrupt to send and receive data, and analyzes the data transmitted by the CAN communication module of the controller area network through the data feedback function. The data is restored to its true value and displayed graphically. The test results show that the system can effectively detect the temperature of the vehicle's dual fuel engine. At the same time, it can be learned that the in-cylinder combustion of the dual fuel engine is relatively flat, and the maximum combustion heat release rate is relatively low; when the load and the rotational speed are low, the combustion duration is relatively long. Keeping other conditions constant, reducing only the nozzle flow area is not conducive to improving the combustion characteristics of the dual fuel engine.
\end{abstract}

Keywords: Special; Heavy Vehicle; Dual Fuel Engine; Comprehensive Parameters; Test; Signal Acquisition.

\section{Introduction}

The key to evaluating the performance of the special heavy-duty vehicle dual-fuel engine is the operating state parameters of the engine. Dual-fuel engines are gaining increasing attention as one of the current trends in internal combustion engines (Chintala \& Subramanian. 2017). In the internal combustion engine test, it is necessary to measure a plurality of physical quantities related to operation, such as speed, torque, power, fuel consumption, pressure, etc.; and the test quantity of the dual fuel engine has gas consumption in addition to the above. At the same time, the temperature in the cylinder rises rapidly due to the superposition of natural gas combustion during switching (Datta \& Mandal 2016). It is also necessary to measure the exhaust temperature of each cylinder. Natural gas is injected into the intake manifold (Khamees \& Flor 2018).

The intake manifold pressure behind the throttle directly reflects the flow of the mixture, which is more accurate than conventional diesel engines.

Like turbocharged natural gas engines, turbocharged dual-fuel engines have problems with low-speed torque and transient response lag when operating in the natural gas-fueled mode.
Therefore, accurate measurement of the pressure before and after the turbocharger is also crucial.

With increasingly stringent emission regulations and energy constraints (Rüger et al. 2017), finding clean and efficient alternative energy sources is the top priority for the internal combustion engine industry. Natural gas fuel has great potential as an alternative fuel for petroleum, which can save oil consumption and effectively reduce harmful emissions such as NOx and PM. Therefore, the special heavy-duty vehicle dual-fuel engine has become one of the hotspots in the current research of the internal combustion engine industry. By properly controlling the ratio of diesel and methanol, effectively controlling the ignition process in the cylinder is the key to achieving efficient and clean combustion.

The design and development of the calibration system for the dual-fuel engine of special heavy vehicles is the necessary condition for achieving optimal matching control of the engine.

At present, the comprehensive parameter test system for dual-fuel engines of special heavy vehicles at home and abroad has been quite mature. Typical examples abroad are the VISION system developed by ATI and the CAMEO system developed 
by Austrian AVL. Domestically, there are gasoline electrical control test systems developed by Tsinghua University and online test systems based on Window platform designed by Beijing Institute of Technology.

However, only Jiangsu University has developed the comprehensive parameter test system for electronically controlled LPG-diesel/methanol dualfuel engines.

In order to study the comprehensive parameters of the special fuel vehicle dual fuel engine (Saratale et al. 2017), the LabVIEW-based DAQ data acquisition module and serial communication module are designed. The electronic control unit strategy is used to control the acquisition, transmission and transmission of the engine integrated parameter data.

Trying to solve the problem that the traditional engine test bench test has poor real-time performance, and human error affects the test accuracy.

Provide conditions and data support to optimize matching engine control parameters (Li et al. 2016) to achieve better power and economy based on emissions.

\section{Materials and Methods}

\subsection{Comprehensive parameter test system for vehicle dual fuel engine}

The research object of this paper is Yuchai YC6K420 series inline six-cylinder CNG/special heavy vehicle dual fuel engine. The natural gas of this special heavy-duty vehicle engine uses a single-point injection method. The main data collected are the exhaust manifold temperature of each cylinder and the temperature before the two turbines.

They correspond to the exhaust manifold temperature of the first three cylinders and the last three cylinders through the cooling water jacket.

The temperature after the turbine is the temperature of the exhaust manifold after the work of the turbocharger, the cooling water outlet, the inlet temperature, and the 1-cylinder cylinder pressure.

The intake manifold pressure can be used to judge the pressure after intercooling.

The exhaust pressure before and after the turbine can determine the turbocharger's work, engine speed and cam position. In addition, based on the characteristics of the dual fuel engine, the throttle oxygen sensor data, the exhaust pipe temperature, the overall oil, and the gas consumption value are also extremely important for energy saving.

Tables 1 and 2 respectively describe the specific sensor types and engine main parameters of the special heavy vehicle involved in the test system.
Table 1. Sensor type

\begin{tabular}{|c|c|}
\hline $\begin{array}{c}\text { Measurement } \\
\text { parameters }\end{array}$ & Sensor Type \\
\hline $\begin{array}{c}1-6 \text { cylinder exhaust } \\
\text { manifold temperature }\end{array}$ & $\begin{array}{c}\text { OMEGAK } \\
\text { thermocouple }\end{array}$ \\
\hline $\begin{array}{c}\text { Temperature before and } \\
\text { after turbine }\end{array}$ & $\begin{array}{c}\text { OMEGAK } \\
\text { thermocouple }\end{array}$ \\
\hline 1 cylinder & $\begin{array}{c}\text { AVL High Temperature } \\
\text { Pressure Sensor }\end{array}$ \\
\hline $\begin{array}{c}\text { Intake main pressure } \\
\text { Turbine front and rear }\end{array}$ & $\begin{array}{c}\text { AVL pressure sensor } \\
\text { resistant pressure- } \\
\text { sensor }\end{array}$ \\
\hline Speed, cam position & $\begin{array}{c}\text { Magneto-electric } \\
\text { sensors }\end{array}$ \\
\hline $\begin{array}{c}\text { Temperature of entry } \\
\text { and exit of cooling water }\end{array}$ & $\begin{array}{c}\text { OMEGAPt 100 thermal } \\
\text { resistor }\end{array}$ \\
\hline Oil and gas consumption & $\begin{array}{c}\text { Precision mass fuel } \\
\text { consumption meter } \\
\text { (RS485 serial port } \\
\text { communication) }\end{array}$ \\
\hline
\end{tabular}

Table 2. Main parameters of engine

\begin{tabular}{|c|c|c|}
\hline project & unit & parameter \\
\hline Type of launch & - & $\begin{array}{l}\text { Inline, forced water } \\
\text { cooling, } \\
\text { supercharged } \\
\text { medium cold, four- } \\
\text { flush }\end{array}$ \\
\hline Cylinders & jar & 4 \\
\hline Cylinder & $\mathrm{mm}$ & 92 \\
\hline trip & $\mathrm{mm}$ & 94 \\
\hline displacement & $\mathrm{L}$ & 2.498 \\
\hline $\begin{array}{l}\text { Compression } \\
\text { ratio } \\
\end{array}$ & - & 18.5 \\
\hline Rated power & $\begin{array}{c}\mathrm{KW} / \\
\left(\mathrm{r} \cdot \mathrm{min}^{-1}\right)\end{array}$ & $75 / 3600$ \\
\hline $\begin{array}{l}\text { Maximum } \\
\text { torque }\end{array}$ & $\begin{array}{c}(\mathrm{N} \cdot \mathrm{m}) / \\
\left(\mathrm{r} \cdot \mathrm{min}^{-1}\right)\end{array}$ & $260 / 1600-2400$ \\
\hline $\begin{array}{l}\text { Common rail } \\
\text { system }\end{array}$ & - & $\begin{array}{l}\text { BOSCH second- } \\
\text { generation high- } \\
\text { pressure common } \\
\text { rail system }\end{array}$ \\
\hline Diesel injectors & - & Bosch CR 12.0 \\
\hline $\begin{array}{l}\text { Natural gas } \\
\text { injectors }\end{array}$ & - & Bosch EV6 \\
\hline
\end{tabular}

\subsection{System composition}

The main functions of the whole special heavy vehicle dual fuel engine integrated parameter test system include: data acquisition (DAQ) of the sensor, signal conditioning, fuel consumption meter, serial communication of the electronic control unit and the 
upper computer. The specific composition of the test system is shown in Figure 1.

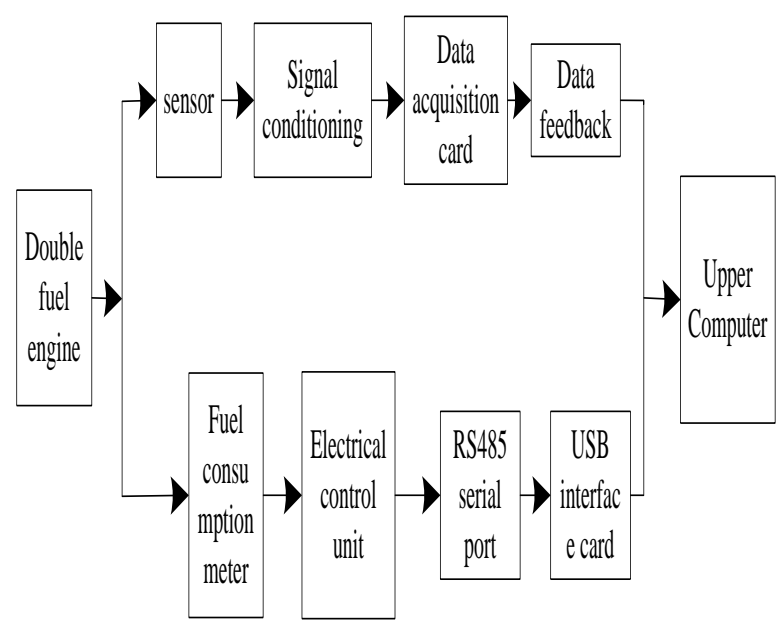

Figure 1: Test the overall architecture of the system

In this paper, the electronic control unit of the system uses Freescale's 32-bit control chip MPC5554 as the main control processor (Behranvand et al. 2018), which can meet the real-time and large data processing requirements of the engine. With a clock speed of up to $132 \mathrm{MHz}$, it has two Enhanced Time Processor Units (eTPUs) and a 64-channel eDMA controller that can perform tasks such as fuel injection and $\mathrm{AD}$ acquisition without taking up core time resources.

The interrupt controller is capable of handling up to 286 selectable medium priority interrupt sources, ensuring timely processing of engine bursts. It also contains 2 FlexCAN modules, each with 64 buffers, supporting CAN2.0A/B protocol to ensure timely and accurate data transmission and reception.

\subsection{Hardware devices}

\subsubsection{Data acquisition hardware equipment}

In the data acquisition process, by analyzing the characteristics of the dual fuel engine integrated parameter measurement signal, NI PXI 6251 acquisition card is used to realize the signal acquisition of each analog quantity (Priya et al. 2018). As the latest $M$-series acquisition card from NI, the FIFO buffer for input and output is much higher than the previous series. The multiplexed PXI 6251 capture card can greatly expand the data acquisition channel with a limited number of analogto-digital converters to meet the number of sensor signals to be acquired in Table 1.

Different from the traditional PCI bus acquisition card, the PXI bus acquisition card can achieve high acquisition rate under more complicated conditions and meet the requirements of fast response of engine signals.
The SCXI module is the NI-specific module designed for all types of signal conditioning, especially for use with M-series capture cards (Pasternak et al. 2016). In this system, the SCXI module is mainly used to provide excitation of threewire Pt thermal resistance, cold junction compensation of thermocouple and voltage signal conditioning (Nerat \& Đani Juričić 2016).

The engine speed collected by the Hall sensor is a square-like signal. To improve accuracy and avoid clock interference with the SCXI module, the counter-specific PXI 6602 Timing acquisition card is used. The structure of the DAQ hardware is shown in Figure 2.

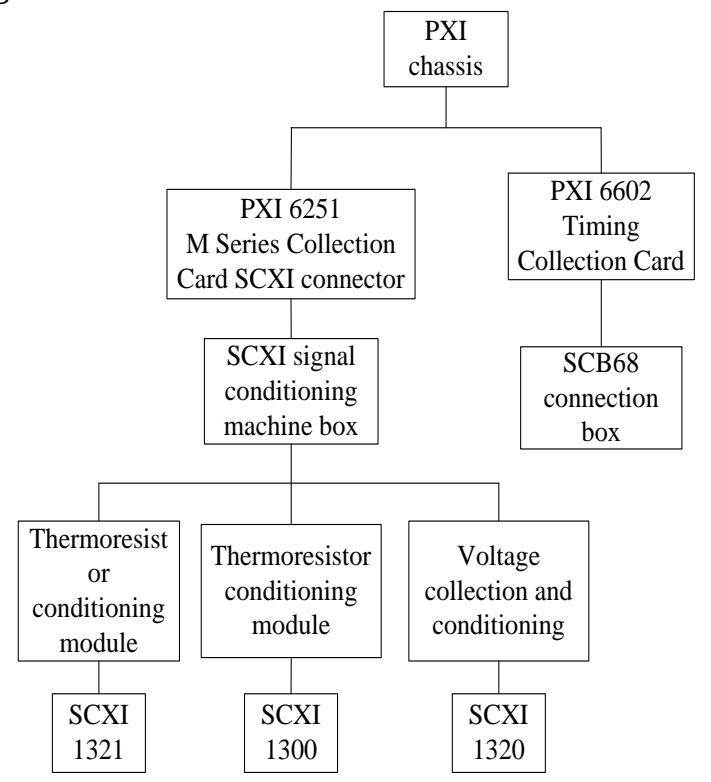

Figure 2: Hardware structure of data acquisition $(D A Q)$

\subsubsection{Measuring equipment for fuel consumption and gas consumption}

The measurement of fuel consumption and gas consumption of a special heavy-duty vehicle dualfuel engine requires extremely high precision.

A mass flow meter from three German Endress + Hauser $(\mathrm{E}+\mathrm{H})$ companies is used to form the combination of fuel consumption and gas consumption. Two of them measure incoming and return oil separately, and their difference is the fuel consumption of the dual fuel engine.

The other is used as a gas consumption meter to measure the consumption of compressed natural gas. This type of flow meter is based on the Coriolis force mass flow measurement principle, and complex calculations are handled by the PLC of the fuel consumption meter (Zheng et al. 2017). It only needs to communicate the data stored in the RAM of the PLC with the host computer through the RS485 serial port, and display it in the test interface after parsing. 
According to the flow meter technical manual, the LabVIEW test system based on the Modb us_RTU protocol must be designed.

Its main function is used for signal communication and data analysis, and the resolution standard adopts the IEEE745 floating point number standard. In the fuel consumption measurement program, two flow meter values are also calculated (Yan et al. 2017) in order to realize real-time display and storage of fuel consumption and gas consumption data (Wei et al. 2017).

\subsubsection{USB interface card}

The Controller Area Network (CAN) communication module is used to exchange data between the host computer and the electronic control unit of the calibration system (Wang 2016).

The system adopts USB-CAN interface card and supports CAN2.0A/B protocol.

The maximum communication rate is up to $1 \mathrm{Mbps}$, the maximum traffic is 3000 frames/s, and 200 message frames can be buffered.

It has a good electromagnetic isolation design (Liu et al. 2017) to meet the requirements for use in the engine rig.

\subsection{Test system software development}

The software development of the test system is mainly divided into two parts: DAQ acquisition, RS485 serial communication and data feedback between the electronic control unit and the host computer.

\subsubsection{DAQ acquisition}

(1) DAQ acquisition procedure flow

The DAQ acquisition program flow uses the sequential structure to build each module program in turn.

Continuous acquisition is used to continuously collect data from each channel in chronological order (Choudhury \& Padak 2016).

The data collection process is shown in Figure 3.

The DAQmx timing function selects "Continuous Sampling". Acquisition begins after the DAQmx start task function is called. In each iteration, the DAQmx Read function returns after waiting and reading the required sample points.

The DAQ data collection process is shown in Figure 3.

(2) DAQ acquisition program design

The system data acquisition program mainly includes channel creation, configuration and signal acquisition (Walsh et al. 2016), namely data reading, filtering conditioning, data display and saving.

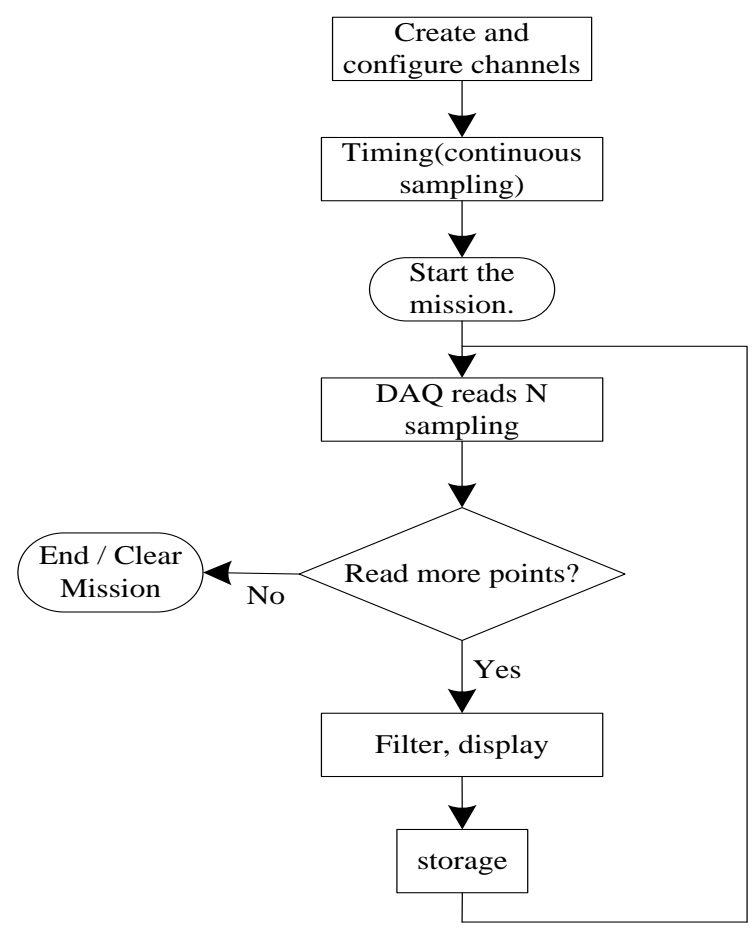

Figure 3 DAQ data acquisition flowchart

Creating and configuring each acquisition channel shall be based on the characteristics and requirements of the signal to be tested (Saxena et al. 2017), using LabVIEW's polymorphic VI selection function to create a configuration physical channel, including analog channels for measuring various temperatures and pressures, and for a counter channel that measures the speed signal shaped by the Schmitt trigger. Modify the channel parameters according to the characteristics of the engine test. For example, the cooling water temperature RTD thermal resistance measurement range is $0-100{ }^{\circ} \mathrm{C}$, the corresponding jumper configuration (Moro \& Helmers 2017) must be configured on the hardware to obtain the most accurate acquisition value.

The timing link, that is, the sampling clock for configuring the analog input, must be configured with the sampling rate, the number of samples per channel, and the sampling mode. The sampling rate refers to the acquisition rate of the device on each channel, which determines the number of analog-todigital conversions per second. The maximum sampling rate of the PXI 6251 acquisition card selected this time is 1 (MS•s-1). In this paper, the multiplexing mode is selected. The sampling rate formula is as follows:

$$
\text { Maximum sampling rate for each channel }=\frac{1\left(M S \bullet s^{-1}\right)}{\text { Total number of channels }}
$$


The test system uses a total of 24 analog channels, the highest sampling rate can reach 4.1 (kS•s-1), which can meet the needs.

According to the Nyquist sampling theorem, the sampling rate must be greater than twice the highest signal frequency. The higher the sampling rate, the less likely the distortion is to be acquired, but the high sampling rate is more demanding for the background digital processing system.

The frequency of the currently input analog signal such as engine temperature, pressure, etc. is temporarily not considered. Sampling 2 points per second is sufficient to meet the requirements (Wang et al. 2016), and the amount of data storage is not too large.

The samples number per channel is the length of data read from the channel each time. The signal collected by NI is read from the buffer (FIFO buffer) of the capture card channel. The key to configuring this value is to avoid buffer overflow. Generally, it has the relationship with the sampling frequency of $1 / 2$, and is configured as 1 in the program.

Based on the signal conditioning function provided by NI hardware devices, analog signal acquisition uses LabVIEW's own average filtering VI directly in the program.

In the counter collection of the rotational speed, in order to avoid excessive signal fluctuation due to missing teeth, the extreme value average filtering procedure after removing the maximum and minimum values is prepared by using the array. Using the producer-consumer architecture, producer loops and consumer cycles operate independently of each other ( $\mathrm{Li}$ et al. 2017). The collected data is transmitted to the consumer for processing, saving, and the like in a queue manner.

Use the Express VI assistant to add TDMS data storage, store the collected data of each channel in a newly created TDMS document, avoiding the cumbersome manual recording.

\subsubsection{Electronic control unit strategy design}

(1) Communication process design

In order to ensure the real-time performance of the test system and reduce the burden on the system, all the data to be sent and received are filled in according to a unified data format, and the variable names of the data are not marked.

The upper computer and the lower computer parse the data by the ID number of the CAN message frame and the byte number in the message frame.

Each data specifies two bytes, and each data frame has a data segment of 8 bytes.

Table 3 is the data format of the CAN message frame defined by the test system.

Table 3. CAN Message Frame Data Format

\begin{tabular}{|c|c|c|c|c|c|}
\hline ID & $\begin{array}{c}\text { Send/ } \\
\text { receive }\end{array}$ & Data1 & Data2 & Data3 & Data4 \\
\hline 100 & receive & \begin{tabular}{|c|} 
Target orbital \\
pressure
\end{tabular} & $\begin{array}{l}\text { Proportional } \\
\text { coefficient P }\end{array}$ & $\begin{array}{l}\text { Integration } \\
\text { coefficient I }\end{array}$ & $\begin{array}{c}\text { Differential } \\
\text { coefficient D }\end{array}$ \\
\hline 101 & receive & $\begin{array}{c}\text { Main injection } \\
\text { amount }\end{array}$ & $\begin{array}{l}\text { Main Spray } \\
\text { Angle }\end{array}$ & $\begin{array}{c}\text { Post-injection } \\
\text { amount }\end{array}$ & Spray angle \\
\hline 102 & receive & Stop sign & - & - & - \\
\hline 103 & receive & Spray volume & Spray angle & - & - \\
\hline 201 & sending & speed & $\begin{array}{c}\text { Actual orbital } \\
\text { pressure }\end{array}$ & $\begin{array}{c}\text { Target orbital } \\
\text { pressure }\end{array}$ & $\begin{array}{c}\text { OMU space } \\
\text { occupancy ratio }\end{array}$ \\
\hline 202 & sending & $\begin{array}{c}\text { Actual main } \\
\text { injection }\end{array}$ & $\begin{array}{c}\text { Actual main } \\
\text { injection angle }\end{array}$ & $\begin{array}{c}\text { Actual post- } \\
\text { injection volume }\end{array}$ & $\begin{array}{c}\text { Actual rear } \\
\text { injection angle }\end{array}$ \\
\hline 203 & sending & $\begin{array}{l}\text { Operating } \\
\text { conditions }\end{array}$ & - & - & - \\
\hline 204 & sending & $\begin{array}{c}\text { Oil } \\
\text { temperature }\end{array}$ & Oil pressure & $\begin{array}{c}\text { Intake } \\
\text { temperature }\end{array}$ & Intake pressure \\
\hline 205 & sending & $\begin{array}{c}\text { Actual amount } \\
\text { of alcohol } \\
\text { sprayed }\end{array}$ & $\begin{array}{c}\text { Actual amount of } \\
\text { alcohol sprayed }\end{array}$ & $\begin{array}{l}\text { Cooling water } \\
\text { temperature }\end{array}$ & $\begin{array}{c}\text { Natural gas } \\
\text { pressure }\end{array}$ \\
\hline
\end{tabular}

The electronic control unit uses the cycle interrupt to send and receive data, and the cycle interrupt is $10 \mathrm{~ms}$.

In order to ensure that the electronic control system can quickly respond to the data received by the CAN, the CAN receiving task is processed every $10 \mathrm{~ms}$.
If there is no data reception, the original control parameters are kept unchanged (Dhanasekaran \& Mohankumar 2016).

Otherwise, the received data is parsed and the corresponding control parameter quantity is modified. 
In order to monitor the engine working condition to ensure the normal operation of the engine, the electronic control unit sets the CAN sending task, and the task period is set to $50 \mathrm{~ms}$. Figure 4 shows the flow chart of the electronic control unit CAN communication.
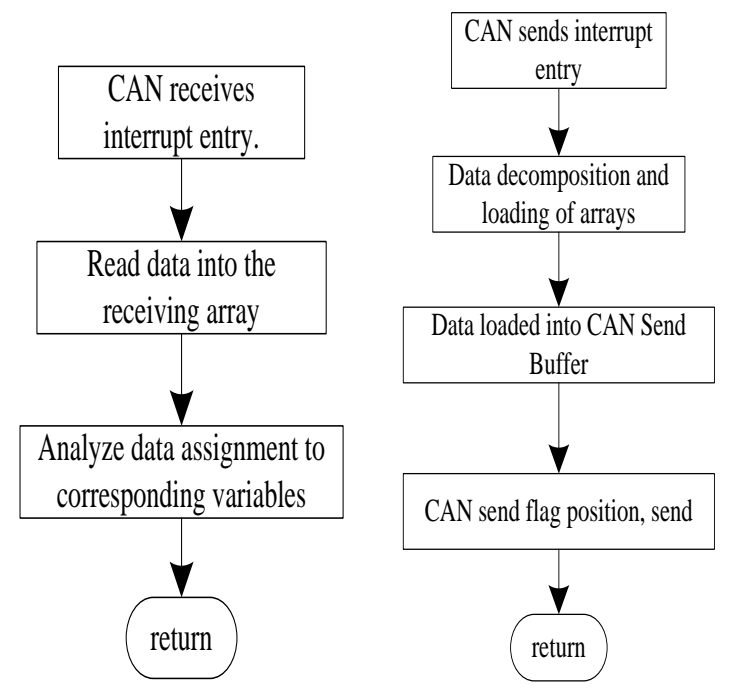

Figure 4: CAN letter flow for electrical control unit

(2) Data feedback

The data feedback function is responsible for recalculating the data transmitted by the CAN communication module to a real value and displaying it in a graphical manner.

According to different data types, the feedback interface is divided into three major areas: engine operating parameter map area, engine status feedback area and control parameter feedback area.

The engine operating parameter map displays parameters such as engine speed, common rail pressure, and cooling water temperature in the form of an image. The engine status feedback zone displays the engine operating status and current operating conditions in numerical form.

The control parameter feedback area displays the actual electronic control parameters of the engine, such as the spray pulse width and the alcohol spray angle.

The LabView Registration Event feature is used to register CAN receive tasks for user-defined events. Combined with the event trigger function, the data feedback automatically collects and displays the received data in real time without human intervention (Wang et al. 2016).

Figure 5 is a flow chart of the data feedback function.

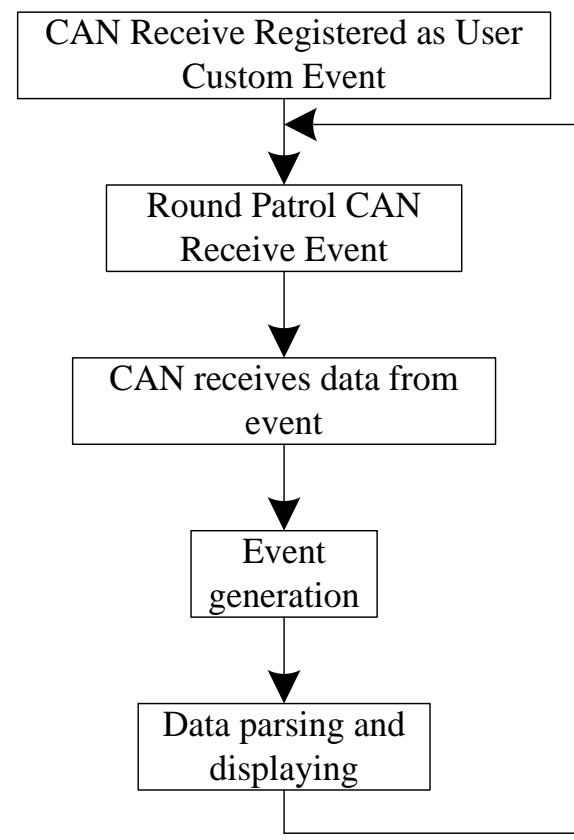

Figure 5 Data feedback function flow chart

\section{Experimental Analyses}

The main technical parameters of the experimental engine are shown in Table 4.

When refilling, the measured volumetric contents of various gases are Methane 96\%, Nitrogen 2.5\%, $1.25 \%$ of carbon dioxide, and other gas content is 0 . $25 \%$.

Table 4. Main technical parameters of engine

\begin{tabular}{|c|c|}
\hline model & 6108 \\
\hline $\begin{array}{c}\mathrm{D} \times \mathrm{S} / \\
\mathrm{m} \times \mathrm{mm}\end{array}$ & $108 \times 125$ \\
\hline displacement/L & 6.87 \\
\hline $\begin{array}{c}\text { Compression ratio } \\
\text { Supply advance } \\
\text { angle/static } \\
\text { recommended value }\end{array}$ & 16 \\
\hline $\begin{array}{c}\text { Number of nozzles X } \\
\text { aperture/mm }\end{array}$ & $2^{\circ} \mathrm{CA}$ \\
\hline
\end{tabular}

\subsection{Temperature error analysis}

After the test system designed by the above process, the comprehensive parameter test and monitoring of the special fuel vehicle dual fuel engine is realized to a certain extent. 
After the test system designed by the above process, the comprehensive parameter test and monitoring of the special fuel vehicle dual fuel engine is realized to a certain extent. In order to verify the test accuracy of the system, the calibration is performed by using a standard signal generator and the like, and the comparison test is performed with the theoretical calculation data after the startup test. More representative is the inspection of the thermocouple signal. The test system includes six cylinder exhaust temperatures. The front and rear exhaust temperatures of the turbine are measured by thermocouples. Therefore, the accuracy of thermocouple signal acquisition is particularly important.

The principle of measuring the temperature of the thermocouple is based on a drawn thermocouple index table, and the measured potential difference between the positive and negative electrodes is in one-to-one correspondence with the corresponding temperature value, thereby obtaining the measured temperature. Any millivolt potential difference can be input to the sensor using the Fluke 744 standard signal generator. In the host computer, the temperature obtained by the test system can be read out. The measurement error can be obtained by comparing the K-type thermocouple reference table provided by OME GA.

Taking the three-cylinder exhaust temperature, the six-cylinder exhaust temperature, and the turbine rear exhaust temperature measurement error as an example, the exhaust gas measurement temperature is shown in Figure 6. Analysis of Figure 6 shows that as the exhaust gas measurement temperature gradually increases, the error of the system measurement of three-cylinder exhaust temperature, six-cylinder exhaust temperature, and turbine rear exhaust temperature has some fluctuations, but the overall error is in a decreasing state.

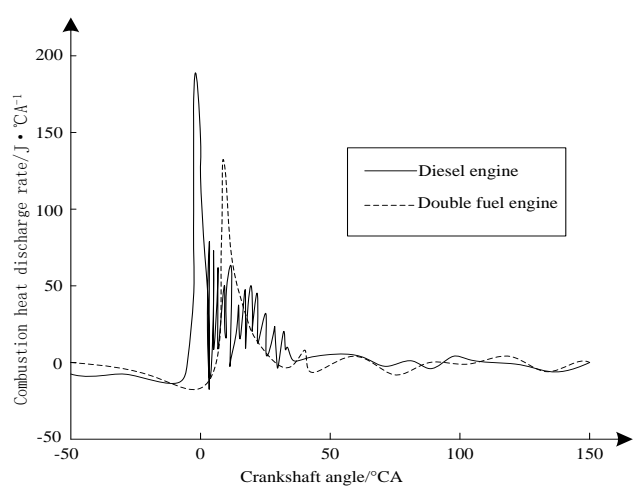

(a) Comparison of exothermic rate at $1200 \mathrm{r} / \mathrm{min}$

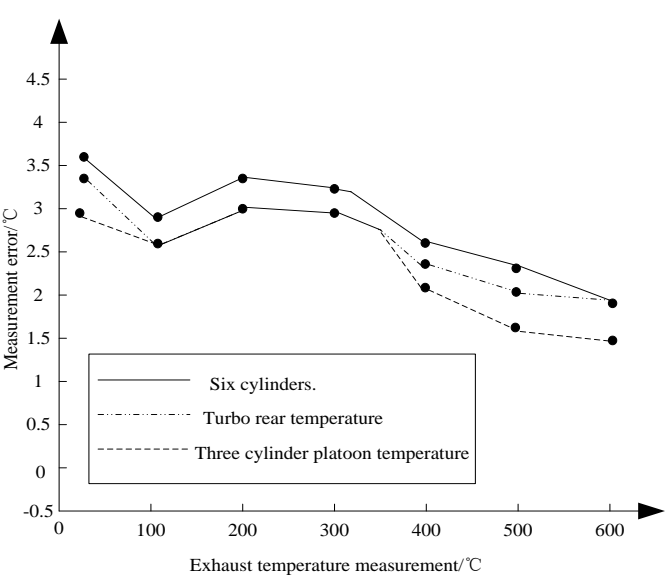

Figure 6 Temperature measurement error of thermocouple

It meets the conventional theoretical requirements, which also shows that the system can effectively detect the temperature of the dual fuel engine.

\subsection{Combustion characteristics of dual fuel engines}

Before analyzing the combustion characteristics of the dual-fuel engine of special heavy vehicles and its influencing factors, the difference between the dual-fuel engine and the diesel engine of special heavy vehicles is briefly analyzed through the comparison of the combustion heat release rate curves.

During the experiment, the rack of the dual fuel engine was located at the idle oil position of the original diesel engine.

Figure 7 is the comparison of the combustion heat release rate of the diesel engine and the special heavy-duty vehicle dual-fuel engine obtained by the test system under external characteristic conditions.

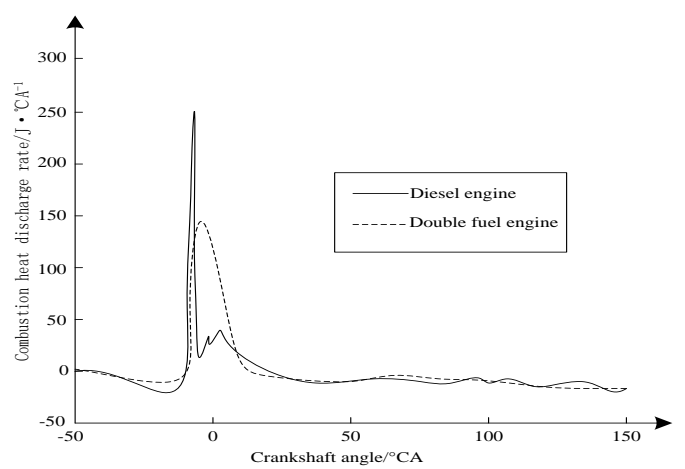

(b) Comparison of combustion heat extrusion rate of calibrated working point

Figure7: Comparison of combustion characteristics of special heavy vehicle double fuel engine and diesel engine

It can be seen from Figure 7 that the in-cylinder combustion of the special heavy-duty vehicle dual- fuel engine is relatively flat, and the highest combustion heat release rate is relatively low. 
When the load and speed are low, the combustion duration is relatively long.

At high speed and high load, the combustion duration of the two is basically the same.

The comparative experimental study of the combustion characteristics under various working conditions of external characteristics shows that the combustion characteristics of the dual fuel engine have the following characteristics compared with the diesel engine:

(1) At low speed and small load, the ignition start time of the special fuel vehicle dual fuel engine is later, the combustion rate is slower, the combustion duration is longer, the highest burst pressure is lower, the pressure rise rate is lower, the combustion noise is small, and the thermal efficiency is reduced.

(2) At high speed and high load, the ignition start time of the dual fuel engine is later, but the

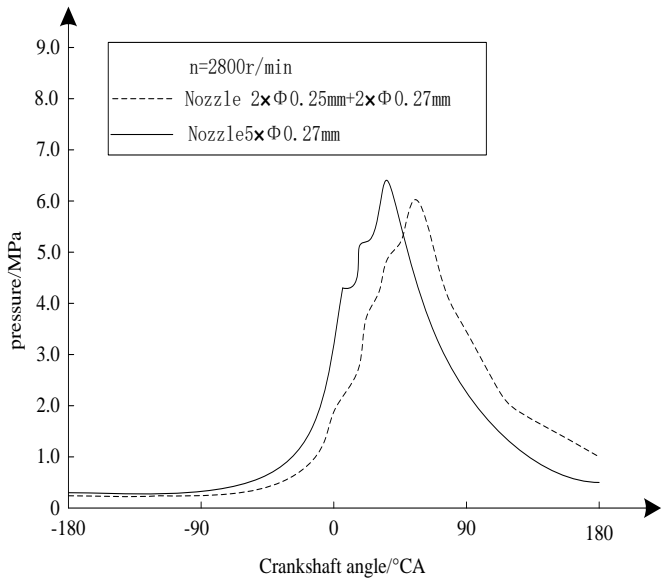

(a) Comparison of the highest explosive force combustion speed is faster, the combustion duration is basically the same as that of the diesel engine, and the highest burst pressure and pressure increase rate are low.

The combustion noise is further reduced with the increase of the load, and the thermal efficiency is basically the same as that of the diesel engine, even slightly higher than that of the diesel engine.

\subsection{Influence of nozzle parameters on combustion characteristics}

This paper systematically tests the effects of two injector parameters on the combustion performance of the special heavy-duty vehicle dual-fuel engine, which are $2 \times \Phi 0.25 \mathrm{~mm}+2 \times \Phi 0.27 \mathrm{~mm}$ and $5 \times \Phi 0.27$ $\mathrm{mm}$, respectively.

The experimental results are shown in Figure 8.

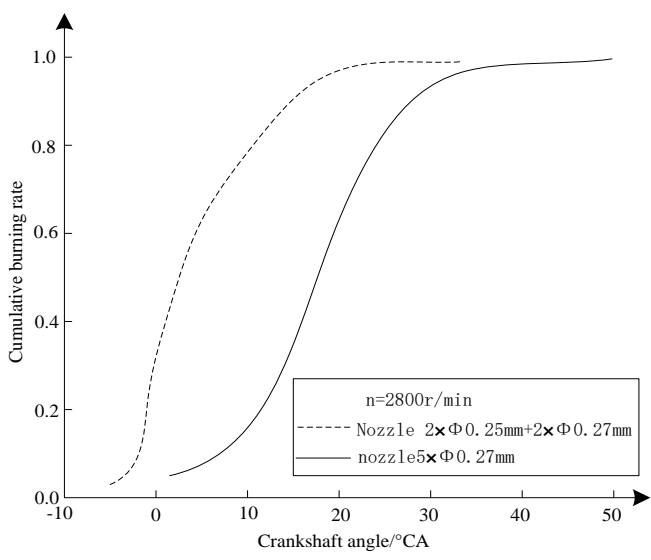

(b) Comparison of cumulative combustion heat extraction rates

Figure: 8 Effect of 2 kinds of fuel injector parameters on combustion performance of double fuel engine of special heavy vehicles

Analysis of Figure 8 shows that keeping the other conditions constant, reducing the nozzle flow area alone is not conducive to improving the combustion characteristics of the dual fuel engine.

The specific performance is that the ignition time is delayed, the burning rate is slowed down, and the burning duration is prolonged. The reason for this change in combustion characteristics is that for a special heavy-duty vehicle dual-fuel engine, increasing the nozzle flow area increases the energy at the initial stage of ignition, which is advantageous for igniting natural gas with a slow propagation rate.

\section{Discussion}

Based on Yuchai YC6K420 series in-line six-cylinder CNG/dual fuel engine special heavy-duty vehicles, the dual-fuel engine integrated parameter test system is constructed to effectively detect and analyze the comprehensive parameters of special heavy-duty dual-fuel engines.

The following conclusions are drawn:

(1) In this paper, for the test characteristics of dual-fuel engine, the thermocouple signal is tested. In this paper, the system measures the error of the three-cylinder exhaust temperature, the six-cylinder exhaust temperature, and the rear-row temperature of the turbine in a decreasing state, which meets the conventional theoretical requirements. This shows that the system can effectively detect the temperature of the vehicle dual fuel engine.

(2) The working condition of the dual fuel engine seriously affects its combustion performance. Compared to low loads, dual fuel engines have the faster burning rate at high loads and reduced combustion duration to the level that is substantially consistent with diesel engines. The combustion noise is further reduced with the increase of the load, and 
the thermal efficiency is increased to be substantially the same as that of the diesel engine, or even slightly higher than that of the diesel engine.

(3) In the cylinder of the dual fuel engine, the fuel is burned evenly and sufficiently. Selecting the nozzle with the large flow area can achieve rapid ignition of natural gas from diesel.

\section{Conclusions}

In the comprehensive parameter test system of the special heavy-duty vehicle dual-fuel engine designed in this paper, the engine analog signal is acquired by the PXI6251 acquisition card, and the fuel consumption and gas consumption meter are used to measure, display and save the fuel consumption and gas consumption data of the engine.

The electronic control unit in the system uses the periodic interrupt to send and receive data, and analyzes the data transmitted by the CAN communication module of the controller area network through the data feedback function. The data is restored to its true value and displayed graphically. Finally, the system effectively detects the temperature of the dual fuel engine of the vehicle, the combustion characteristics of the dual fuel machine and the influence of the nozzle parameters on the combustion characteristics.

This shows that the system can achieve all aspects, accurate measurement and analysis of the comprehensive parameters of the special heavy vehicle dual fuel engine, and has achieved satisfactory results.

\section{References}

[1] Behranvand, E., Mozdianfard, M.R., DiazBejarano, E. 2018. A Comprehensive Investigation of Refinery Preheaters Foulant Samples Originated by Heavy Crude Oil Fractions as Heating Fluids. Fuel 224: 529-536.

[2] Chintala, V., Subramanian, K.A. 2017. A Comprehensive Review on Utilization of Hydrogen in a Compression Ignition Engine under Dual Fuel Mode. Renewable \& Sustainable Energy Reviews 70: 472-491.

[3] Choudhury, N.N., Padak, B. 2016. A comprehensive Experimental and Modeling Study of Sulfur Trioxide Formation in Oxy-Fuel Combustion. International Journal of Greenhouse Gas Control 51: 165-175.

[4] Datta, A., Mandal, B.K. 2016. A Comprehensive Review of Biodiesel as an Alternative Fuel for Compression Ignition Engine. Renewable \& Sustainable Energy Reviews 57: 799-821.

[5] Dhanasekaran, C., Mohankumar, G. 2016. Dual Fuel Mode DI Diesel Engine Combustion with Hydrogen Gas and DEE as Ignition Source.
International Journal of Hydrogen Energy 41(1): 713-721.

[6] Khamees, T.K., Flor, R.E. 2018. A Comprehensive Evaluation of the Parameters That Affect the Performance of In-Situ Gelation System. Fuel 225: 140-160.

[7] Li, H., Liu, S., Liew, C. 2017. An Investigation of the Combustion Process of a Heavy-Duty Dual Fuel Engine Supplemented With Natural Gas Or Hydrogen. International Journal of Hydrogen Energy 42(5): 3352-3362.

[8] Li, Y., Ming, J., Chang, Y. 2016. Towards A Comprehensive Understanding of the Influence of Fuel Properties on the Combustion Characteristics of A RCCI (Reactivity Controlled Compression Ignition) Engine. Energy 99: 6982.

[9] Liu, J., Gong, N.N., Chen, J.E. 2017. Research of Crack Detection and Delay Crack Propagation on Engine's Nonlinear Rotor. Computer Simulation 34(10): 40-44.

[10] Moro, A., Helmers, E. 2017. A New Hybrid Method for Reducing the Gap between WTW and LCA in the Carbon Footprint Assessment of Electric Vehicles. International Journal of Life Cycle Assessment 22(1): 4-14.

[11] Nerat, M., Đani, Juričić. 2016. A Comprehensive 3-D Modeling of a Single Planar Solid Oxide Fuel Cell. International Journal of Hydrogen Energy 41(5): 3613-3627.

[12] Pasternak, G., Greenman, J., Ieropoulos, I. 2016. Comprehensive Study on Ceramic Membranes for Low-Cost Microbial Fuel Cells. Chemsuschem 9(1): 88-96.

[13] Priya, K., Sathishkumar, K., Rajasekar, N. 2018. A Comprehensive Review on Parameter Estimation Techniques for Proton Exchange Membrane Fuel Cell Modelling. Renewable \& Sustainable Energy Reviews 93: 121-144.

[14] Rüger, C.P., Schwemer, T., Sklorz, M. 2017. Comprehensive Chemical Comparison of Fuel Composition and Aerosol Particles Emitted From A Ship Diesel Engine by Gas Chromatography Atmospheric Pressure Chemical Ionisation Ultra-High Resolution Mass Spectrometry with Improved Data Processing Routines. European Journal of Mass Spectrometry 23(1): 28-39.

[15] Saratale, G.D., Saratale, R.G., Shahid, M.K. 2017. A Comprehensive Overview on Electro-Active Biofilms, Role of Exo-Electrogens and Their Microbial Niches in Microbial Fuel Cells (MFCs). Chemosphere 178: 534-547.

[16] Saxena, V., Kumar, N., Saxena, V.K. 2017. A Comprehensive Review on Combustion and Stability Aspects of Metal Nanoparticles and Its Additive Effect on Diesel and Biodiesel Fuelled C.I. Engine. Renewable \& Sustainable Energy Reviews 70: 563-588. 
[17] Walsh, P., Garbalena, M., Schug, K.A. 2016. Rapid Analysis and Time Interval Deconvolution for Comprehensive Fuel Compound Group Classification and Speciation Using Gas Chromatography-Vacuum Ultraviolet Spectroscopy. Analytical Chemistry 88(22): 11130.

[18] Wang, L.G. 2016. Automobile Engine Connecting Rod Parameter Detection Technology Based on Machine Vision. Automation \& Instrumentation (5): 103-104.

[19] Wang, Q., Wang, B., Yao, C. 2016. Study on Cyclic Variability of Dual Fuel Combustion in a Methanol Fumigated Diesel Engine. Fuel 164(2016): 99-109.

[20] Wang, R.L., Xiao, Y.H., Hou, X.P. 2016. Test Data Automatic Generation Method for
Communication of Uncertainty MPI Parallel Program. Journal of Jilin University (Science Edition) 54(6): 1378-1382.

[21] Wei, N., Li, G., Liu, H.X. 2017. Design of Armored Vehicles Lead-Acid Battery State Monitoring System. Chinese Journal of Power Sources 41(9): 1346-1349.

[22] Yan, X.Y., Yang, S.C \& He, H.2017.Load Adaptive Control Based on Frequency Bifurcation Boundary for Wireless Power Transfer System. Journal of power supply 15(2): 159-165.

[23] Zheng, Y., Fang, D.D., Zeng, C.N. 2017. Design and Realization of the Radiated Immunity Measure System Base on Multi-Platform. Journal of China Academy of Electronics and Information Technology 12(3): 271-277. 